\title{
The Quality Improvement of City Passenger Traffic on The Basis of the Passenger Capacity Control
}

\author{
Nicolay Trubin, Elena Bondarenko, Igor Lyubimov*, and Nail Sultanov \\ Orenburg State University, 13 Prospect Pobedy, Orenburg, 460018, Russia
}

\begin{abstract}
The article presents the reasoning of the development methodology of the quality improvement of city passenger automobile traffic on regular routes based on the modern means use at the accounting of the bus passengers occupancy and intermedia, processing and the information use about the bus fullness by passengers for dispatching management of vehicles operating mode on route.
\end{abstract}

\section{Introduction}

The main objective of the production organization and planning in each motor transportation enterprise is the rational combination and the use of all production resources for the purpose of the maximum transport work performance while supplying the population by passenger traffic.

In the unified transport system of Russia the motor transport takes the leading place in the population service. Now more than 80 million passengers are transported only by the vehicles fleet daily according to the Ministry of transport of the Russian Federation $[1,2$, 3].

Bus transport represents the most mass type of the passenger motor transport. It plays an essential role in the unified transport system of the country. More than $60 \%$ of the transportations volume from all types of mass passenger transport account for its share, and the passenger turnover makes about $40 \%$.

\section{Material and methods}

The bus is the only type of mass passenger transport in the majority of the towns. Buses carry out the transport connection in all territory of the town and promote the integration of all town districts in a single town complex. On intra-regional, inter-regional and intraprovincial routes the bus transport provides the passenger transportations to railway stations, river ports, seasonal dachas, bus stations of distant bus traffic. In the long-distance service the bus transport carries out the additional work of the railway and air transport. In

* Corresponding author: 1yubimovii@gmail.com 
some cases the route of distant bus traffic is more rectilinear and the passengers' delivery to the destination is carried out by the buses with considerable saving of time.

The scientific research, which is directed to the quality improvement of city passenger automobile traffic on regular routes on the basis of the modern means use at the accounting of the bus passenger occupancy, is intended for the replacement of the existing natural manual methods in passenger traffic researches and for the transition to use the modern technical means and technologies.

The tools allow to carry out stage-by-stage creation of the permanent automated system of monitoring of actually executed services in passenger transportations.

The development of the complex for the city passenger automobile traffic management has to become the information basis for the improvement of the system control of the routed public land passenger transport. The permanent monitoring system has to provide the governing bodies of all levels with the assessment information of the current state of transportations and the objective needs of the population in this type of service, for the problems solution of the public transport service improvement and its perspective development.

The mathematical model of the adaptive management is developed for the purpose of the quality improvement of city passenger traffic. This model considers the characteristics of the rolling stock and their fullness on stopping points [4].

\section{Theory}

For the determination of the necessary number of buses during the work on a route we use the known dependence in which we will replace the static efficiency of capacity with a variable $\gamma_{c a p}(t)$, characterizing the coefficient value in $t$ time point:

$$
B_{r}=\frac{365 \cdot Q_{n} \cdot \gamma_{\text {cap }}(t) \cdot \alpha_{\text {cap }} \cdot V_{s} \cdot T_{\text {ord }} \cdot \beta}{l_{a v} \cdot k_{\text {days }} \cdot k_{\text {dir }}},
$$

where $Q_{n}$ - the annual volume of transportations on a route, pass.; $l_{\mathrm{av}}$ - the average range of a trip for one passenger, $\mathrm{km} ; k_{\text {days }}, k_{\text {dir }}$ - unevenness coefficient of transportations respectively on hours of days and in the directions of routes; $q_{a v}$ - the average capacity of the vehicle, pass.; $\gamma_{c a p}(t)$ - the capacity coefficient of the vehicle in $t$ moment; $\alpha_{c a p}-$ the capacity coefficient of the vehicle; $V_{s}$ - service speed, $\mathrm{km} / \mathrm{h} ; T_{\text {ord }}$ - the duration of the vehicle in order, h.; $\beta$ - efficiency of vehicle mileage.

The headway of buses $\left(I_{m}, \mathrm{~min}\right)$ is determined by a formula:

$$
I_{m}=\frac{T_{r e v}}{B_{r}}
$$

where $T_{\text {rev }}$ - time of reverse run.

The headway as the function of the capacity efficiency is:

$$
I=f\left(\gamma_{\text {cap }}\right),
$$

The capacity efficiency $\gamma_{c a p}$ is determined by a formula

$$
\gamma_{\text {cap }}=\frac{q_{\text {pass }}^{\text {actual }}}{q_{\text {pass }}^{\max }}
$$

where $q_{\text {pass }}^{\text {actual }}$ - the actual number of passengers, pass.; $q_{\text {pass }}^{\max }-$ passenger capacity of the bus, pass. 
The formation result is expression (5).

The criterion function of the volume optimization of the transported passengers:

$$
\begin{aligned}
& Q_{n}=\frac{365 \cdot B_{r} \cdot q_{\text {pass }}^{\max } \cdot \alpha_{\text {cap }} \cdot V_{s} \cdot T_{\text {ord }} \cdot \beta}{l_{\text {av }} \cdot q_{\text {max }} \cdot k_{\text {days }} \cdot k_{\text {dir }}} \rightarrow \max \\
& I_{\text {min }}<I<I_{\text {max }} \\
& I= \begin{cases}\uparrow, \text { if } & \gamma_{\text {cap }} \geq 0,8\left(q_{n} \approx q_{\max }\right) \\
\downarrow, \text { if } & \gamma_{\text {cap }}<0,8\end{cases}
\end{aligned}
$$

The realization of the developed model in practice means the reduction of the vehicle headway at the fullness which is close to maximum and the increase in an interval at insufficient fullness $[5,6]$.

The algorithm of the adaptive management of the passenger vehicle work is developed on the basis of the created mathematical model (figure 1) $[7,8]$.

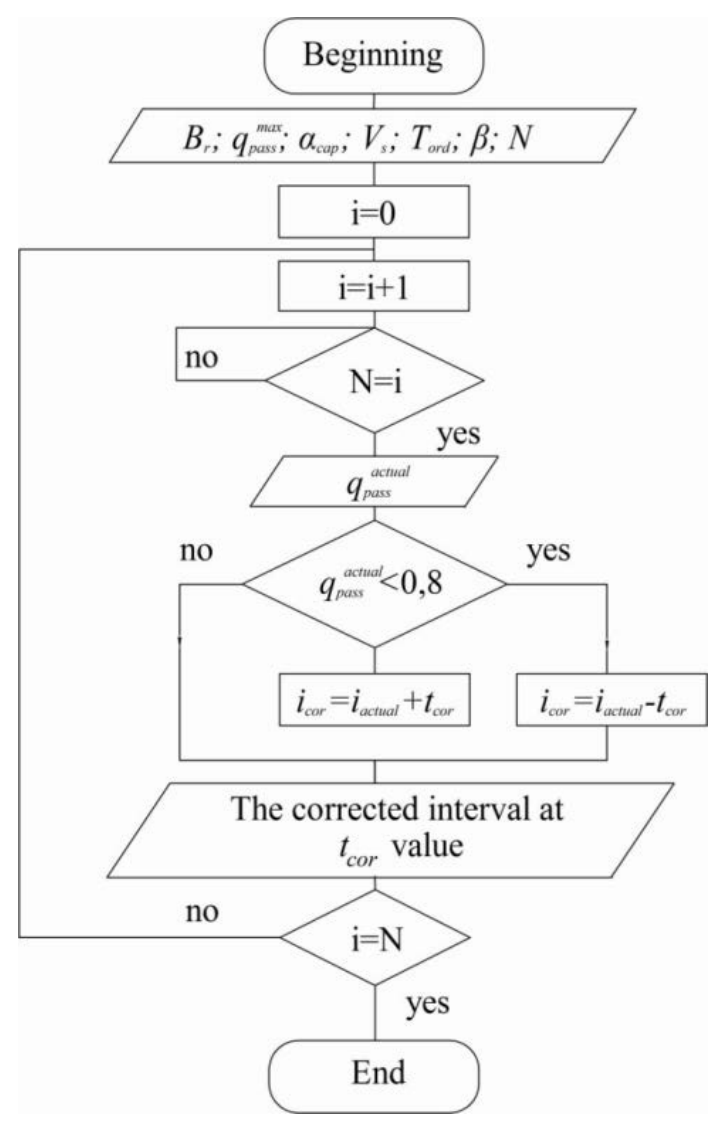

Fig. 1. The algorithm of the adaptive management of the passenger vehicle

The methodology of the experimental study conducting, including the justification and the choice of technical means, their placement on passenger route vehicles, the development of the control technology for the vehicle fullness, and also the technology of the headway management, is developed for the experimental realization of theoretical provisions [9]. 
Thus, the combination of technical means for the vehicles occupancy monitoring, transporting passengers on regular city routes, with the methods of the intellectual management of the rolling stock work on a route creates the objective prerequisites of the improvement of the passenger service quality consisting in the waiting time reduction of the vehicle, in the comfortableness increase of a trip, on the one hand, and the costs optimization of the rolling stock operation by a carrier - on the another [10-15].

\section{Results and Discussion}

The implementation of the developed theoretical thesis at the organization of passenger transportations on route No. 21 of Orenburg allowed to reduce the movement interval for 1 min. in rush hours, to increase the capacity of the buses working at a route at this time that led to the reduction of vehicle wait time for $7 \%$, and to the comfortableness of passenger trip - for $27 \%$.

The results of theoretical and experimental studies, the implementation of the developed technique allowed to create the program of priority researches of the following directions:

- the features analysis of different intellectual technologies and methods while processing of the obtained information on the degree of the bus occupancy bus in relation to the management tasks;

- the development of theoretical bases of intellectual management;

- the principles development for the creation of hardware and software means of the intellectual control systems.

\section{References}

1. Bondarenko, E., Goncharov, A., Gorlatov, S., Lyubimov, I., Manaev, K., Melnikov, A., Trubin, N. Concept of municipal road transport. The world of transport and technological machines, 2 (49). Orel, 110-116 (2015)

2. Bondarenko, Ye., Zuyev, A., Lyubimov, I., Manayev, K., Mel'nikov, A. Infrastructure optimization of collection and removal of solid domestic wastes from the settlement territory, in: Vestnik of the Moscow automobile and road construction state technical university (MADI), Moscow, № 4. pp. 92a-96 (2011).

3. Lyubimov, I. Indicators demand for urban passenger transport (by the example of Orenburg). Bulletin of the Orenburg State University, 9 (115), 139-143 (2009)

4. Lyubimov, I., Manayev, K.,Mel'nikov, A., Rassokha, V. The algorithm development for the optimization of the rolling stock and container park at collecting and removing solid domestic wastes. Proceedings of the Tula state university. Technical sciences., Tula, № 4. pp. 174-182 (2011)

5. Liu, R., Smith, M. J. Route choice and signal control: a study of the stability and instability of traffic signal controlled networks. Transportation Research Part B, 77, 123-145 (2015)

6. Lyubimov, I., Sultanov, N., Bondarenko, Ye. To the subject of the rational structure formation of the city passenger transport in Orenburg. Vestnik of the Moscow automobile and road construction state technical university (MADI). № 3. Pp. 21-25 (2009)

7. Lyubimov, I., Sultanov, N. Theoretical bases of perfection transport system. Bulletin of the Orenburg State University, 10, 121-123 (2014) 
8. Lubimov, I., Sultanov, N., Kovrikov ,I. Model of motor transport network in the region (by the example of the Orenburg region). Bulletin of the Orenburg state university, Orenburg, № 10 (129). Pp. 32-37 (2011)

9. Liu, R., van Vliet, D. and Watling, D. 2006. Microsimulation models incorporating both demand and supply dynamics. Transportation Research, 40A, 125-150.Lyubimov, I., Melnikov, A., Trubin, N. The Control System Improvement of the City Motor Transportation Science Direct: Procedia Engineering. Volume 150. Pp. 1192-1199 (2015)

10. Melnikov, A., Lyubimov, I., Manayev, K. Improvement of the Vehicles Fleet Structure of a Specialized Motor Transport Enterprise. Science Direct: Procedia Engineering. Volume 150. Pp. 1200-1208 (2016)

11. Vagapova, N., Portnikov, B., Sultanov, N., Lyubimov, I. Functional processes management of city passenger transportation in: Intellect. Innovations. Investments., Orenburg, № 2, Pp. 49-56 (2009)

12. Varaiya, P. Max pressure control of a network of signalised intersections. Transportation Research Part C, 177-195 (2013)

13. Wardrop, J. Some theoretical aspects of road traffic research, Proceedings of the Institute of Civil Engineers Part II, 1, 325-378 (1952)

14. Webster, F. Traffic Signal Settings, Department of Transport, Road Research Technical Paper No. 39, HMSO, London (1958)

15. Yang, H., Yagar, S. Traffic assignment and signal control in saturated road networks. Transportation Research Part A, 29 (2), 125 - 139 (1995) 